\title{
Misdiagnosis and delayed diagnosis in traumatic intracranial haematoma
}

\author{
S GALBRAITH
}

British Medical fournal, 1976, 1, 1438-1439

\section{Summary}

Out of 51 patients with traumatic intracranial haematoma admitted to a teaching hospital $11\left(22^{\circ}\right)$ died undiagnosed, and out of 307 such patients transferred to the West of Scotland Regional Neurosurgical Centre 111 $\left(36^{\circ}\right)$ had been deteriorating for more than 12 hours in another hospital. In two-thirds of these cases the delay was due to an erroneous diagnosis, either of cerebrovascular accident or of alcoholic intoxication.

\section{Introduction}

Traumatic intracranial haematoma (extradural, subdural, and intracerebral, operated on within 14 days of injury) is a relatively rare complication of head injury. Recovery depends on early diagnosis and prompt treatment, which in turn requires an appreciation of the various types of presentation. Classically, in a patient developing traumatic haematoma there is an initial period of altered consciousness, followed by a lucid interval, after which the conscious level again begins to deteriorate; on the ipsilateral side the pupil becomes fixed and dilated, and on the contralateral side hemiparesis develops. Skull fracture is usually present. This classical syndrome occurs, however, in only a few cases. ${ }^{1-3}$ The most consistent feature is a progressive deterioration in consciousness, and, although some patients may have talked, most will have had a disorder of consciousness continuously from the time of the injury. Failure to appreciate this is one reason why there is sometimes a delay in recognising intracranial haematoma, which may be disclosed for the first time at necropsy. ${ }^{4}$ This paper explores the frequency with which intracranial haematoma is overlooked clinically or its recognition delayed in the west of Scotland.

\section{Patients and methods}

In the West of Scotland Region patients with head injuries are primarily admitted to general hospitals, only those needing specialised facilities being transferred to the regional neurosurgical unit. This is the system used in most of Britain. ${ }^{5}$ The regional neurosurgical unit covers not only the Greater Glasgow area, with its five adult teaching hospitals and one children's teaching hospital, but also a large area of countryside administered by five other area boards, the aggregate population being some $2 \cdot 7$ million.

Only haematomas judged at operation or necropsy to have been the major cause of deterioration or death were considered in this study, "smear" haematomas and clots associated with serious dyruption of the brain being excluded.

Misdiagnosis-A survey was made of all patients with head injuries admitted to one of the teaching hospitals during 1970 to 1974 who had an intracranial haematoma either surgically removed or found at necropsy.

Delayed diagnosis-The medical and nursing records of patients referred to the neurosurgical unit during 12 years (1963 to 1974) with intracranial haematoma were reviewed to determine the interval

Institute of Neurological Sciences, Glasgow G51 4TF

$S$ GALBRAITH, BSC, FRCS, registrar in neurosurgery between the first evidence of deterioration suggestive of an intracranial haematoma and the time of transfer to the unit. Deterioration was considered to be present if there was any alteration in consciousness or if the patient developed pupillary changes or a hemiparesis. Explanations for delayed transfer included an initial diagnosis of either cerebrovascular accident (cerebral embolus, cerebral infarct, spontaneous intracerebral haemorrhage, subarachnoid haemorrhage) or "effect of excess alcohol." The presence of a skuli fracture was also noted.

\section{Results}

Misdiagnosis-Out of 3147 patients with head injuries admitted to the teaching hospital during the study period $51(2 \%)$ developed a haematoma; of these, $11\left(22^{\circ}{ }_{0}\right)$ remained undiagnosed until necropsy. Although 10 of these 11 patients had a skull fracture, the depressed conscious level had been attributed to a cerebrovascular accident in six patients and to excess alcohol in five. Since fewer necropsies are ordered by procurators fiscal than is the custom with coroners in England and Wales the proportion of patients who died with an undiagnosed intracranial haematoma may well be an underestimate; it was smaller than that reported by James and Turner ${ }^{4}$ in a London district in 1951.

Delayed diagnosis-Altogether 307 patients with haematomas were admitted to the neurosurgical unit during the study period. Of these, $111\left(36^{\circ}{ }_{0}\right)$ had had evidence of deterioration for more than 12 hours before transfer. There may, however, have been further patients in whom signs earlier than this were unobserved or unrecorded. Irrespective of the time of operation after injury there were more deaths among patients whose referral was delayed (table I); $48(43 \%)$ such patients were initially suspected of being drunk and $27(24 \%)$ of having had a cerebrovascular accident. In the remaining $36(32 \%)$ patients, although deterioration was noted, presumably either its significance was not recognised or transfer to the unit could not be arranged sooner (table II).

Fractured skull-Of all 53 patients thought to be drunk and all 33 thought to have had a cerebrovascular accident $41(77 \%)$ and 29 $\left(88^{\circ}\right)$ respectively had fractured skulls (table II).

TABLE I-Outcome in cases operated on within and more than 24 hours after trauma

\begin{tabular}{lll|l}
\hline Alive & Dead & Total \\
\hline
\end{tabular}

\begin{tabular}{|c|c|c|c|}
\hline \multicolumn{4}{|c|}{ Patients operated on within 24 hours of trauma } \\
\hline $\begin{array}{l}\text { Referral delayed } \\
\text { Referral not delayed }\end{array}$ & $\left.\left.\begin{array}{r}5\left(31{ }^{\circ}{ }_{0}{ }^{\prime}\right) \\
78\left(66^{\circ}\right)\end{array}\right)\right\} P<0.01$ & $\left.\begin{array}{l}11\left(69^{\circ}{ }^{\circ}\right) \\
41\left(34^{\circ}{ }_{0}\right)\end{array}\right\} P<0.01$ & $\begin{array}{r}16 \\
119\end{array}$ \\
\hline Total & $83(62 " 1)$ & $52\left(39{ }^{\prime \prime}\right)$ & 135 \\
\hline \multicolumn{4}{|c|}{ Patients operated on more than 24 hours after trauma } \\
\hline $\begin{array}{l}\text { Referral delayed } \\
\text { Referral not delayed }\end{array}$ & $\left.\begin{array}{l}77\left(81{ }^{\circ}{ }^{\circ}\right) \\
72\left(94{ }^{\circ}{ }_{0}\right)\end{array}\right\} P<0.02$ & $18\left(\begin{array}{c}\left(19^{\circ}{ }^{\circ}\right) \\
\left(7_{0}, 0\right)\end{array}\right\} P<0.02$ & $\begin{array}{l}95 \\
77\end{array}$ \\
\hline Total & $149\left(87^{\circ},\right)$ & $23\left(13^{\prime \prime}{ }_{11}\right)$ & 172 \\
\hline Grand total & $232\left(76^{\circ}{ }^{\prime \prime}\right)$ & $75\left(24{ }^{\prime \prime}\right)$ & 307 \\
\hline
\end{tabular}

TABLE II-Misdiagnosis and delayed diagnosis in traumatic intracranial haematoma

\begin{tabular}{|c|c|c|c|c|}
\hline & $\begin{array}{l}\text { Missed } \\
\text { diagnosis }\end{array}$ & $\begin{array}{l}\text { Delayed } \\
\text { diagnosis }\end{array}$ & Total & Fracture \\
\hline $\begin{array}{l}\text { Suspected "drunk" } \\
\text { Suspected cerebrovascular }\end{array}$ & 5 & 48 & 53 & $41\left(77 \%_{0}\right)$ \\
\hline $\begin{array}{cc}\text { accident } & \cdots \\
\text { No other diagnosis } & \ldots\end{array}$ & 6 & $\begin{array}{l}27 \\
36\end{array}$ & $\begin{array}{l}33 \\
36\end{array}$ & $\begin{array}{l}29(88 \%) \\
25(69 \%)\end{array}$ \\
\hline Total & 11 & 111 & 122 & $95(78 \%)$ \\
\hline
\end{tabular}




\section{Discussion}

One of the main aims in the management of head injuries is to ensure that complications are prevented or, if this is not possible, recognised soon enough to institute effective treatment. Even with reasonably prompt operations only a proportion of intracranial haematomas may be successfully treated, but this study indicates that when the operation is substantially delayed after clinical signs have been detected the mortality is increased. Indeed, in this series several intracranial haematomas were first discovered at necropsy.

The commonest reason for failing to recognise an intracranial haematoma is mistakenly attributing the depressed conscious level to a cerebrovascular accident or excess alcohol. When neither of these misdiagnoses confuses the issue the reasons are more difficult to determine, and probably more than one factor often plays a part. Much must depend on the reliable recording of changes in the conscious level and the communication of these from nurse to doctor and from one doctor to another in the general hospital, and from the primary surgeon to the neurosurgeon (usually by telephone). Problems may arise at each of these levels: the primary surgeon may underrate what the nurse reports, or the neurosurgeon may undervalue what the primary surgeon reports. So restricted is the number of neurosurgical beds in many British cities that there is often a reluctance to accept head-injured patients for transfer until the diangosis of haematoma is so definite that deterioration is already advanced ${ }^{5}$; this was certainly a problem in Glasgow at times during the period of this study. When a previously lucid patient deteriorates to the extent of being in coma the diagnosis is easy, but when a patient's conscious level is already altered and it becomes deeper it can be less so, particularly for staff who are not trained or experienced in the observation of acutely brain-damaged patients. It was to facilitate such observations and their communication between nurse and doctor, and doctor and neurosurgeon that the Glasgow Coma Scale ${ }^{6}$ was introduced and with it the Glasgow Head Injury Observation Chart. ${ }^{7}$

This study, however, has also defined two clear causes of confusion: the cerebrovascular accident and the drunk. The patient thought to be suffering from the effect of excess alcohol can present a difficult problem, as MacEwan first pointed out in
1879. ${ }^{*}$ If there is clear evidence of clinical deterioration or there are focal neurological signs or there is a fractured skull, then traumatic intracranial haematoma must be excluded before the clinical state is ascribed to alcohol. In a patient who has taken alcohol and is in coma without focal signs or fracture some help may be obtained from estimating the blood alcohol concentration; if it is under $43.4 \mathrm{mmol} / 1(200 \mathrm{mg} / 100 \mathrm{ml})$ altered consciousness is unlikely to be due to alcohol alone. ${ }^{9}$ Whether a traumatic intracranial haematoma is present, however, can be resolved only by further investigation.

In the patient suspected of having had a cerebrovascular accident the detection of a fractured skull is the best clue to management. All but four of the 33 patients with traumatic haematomas whose conditions were incorrectly diagnosed as vascular accidents had skull fractures. By contrast, in a retrospective study of 1000 consecutive patients with cerebrovascular accidents in a local teaching hospital 132 underwent skull $x$-ray examination and not one had a fracture. If a patient suspected of having had a cerebrovascular accident has a skull fracture his condition is likely to be due to a traumatic intracranial haematoma.

Intracranial haematoma may be difficult to diagnose clinically, and the best chance of recognition rests on an awareness by the doctor of the possibility. Even so, there will always be instances of delay in making the diagnosis and even of discovery at necropsy. The EMI scan appears to be a reliable method of detecting haematoma ${ }^{10}$ but it may be some time before it becomes generally available.

\author{
References \\ ${ }^{1}$ McKissock, W, et al, Lancet, 1960, 2, 167. \\ 2 Jamieson, K G, and Yelland, J D N, fournal of Neurosurgery, 1968, 29, 13. \\ 3 McLaurin, R L, and Tutor, F T, fournal of Neurosurgery, 1961, 18, 61. \\ 4 James, T G I, and Turner, E A, Lancet, 1951, 2, 45. \\ 5 Jennett, B, British Medical Fournal, 1975, 3, 267. \\ 6 Teasdale, G, and Jennett, B, Lancet, 1974, 2, 81. \\ 7 Teasdale, G, Galbraith, S, and Clark, K, Nursing Times, 1975, 71, 973. \\ ${ }^{8}$ MacEwan, W, Glasgow Medical fournal, 1879, 11, 1. \\ ${ }^{9}$ Galbraith, S, et al, British fournal of Surgery, 1976, 63, 128. \\ ${ }^{10}$ Galbraith, S, et al, British Fournal of Surgery, 1976, 63, 157.
}

Rheumatism Research Unit, University of Leeds, Leeds LS2 9PJ C F MURRAY-LESLIE, MB, MRCP, Senior registrar in rheumatology V WRIGHT, MD, FRCP, professor of rheumatology reading of the cervical spine radiographs in ignorance of the groups to which they belonged showed no significant difference in the prevalence of either intervertebral disc degeneration or intraforaminal osteophyte protruion using conventional grading methods. Measurement of the minimum anteroposterior diameter of the cervical spinal canal, the anteroposterior diameters of the cervical vertebral bodies, and the ratio of intervertebral disc height to adjacent vertebral body height in the cervical spine, however, showed a consistent trend to smaller measurements in the carpal tunnel group. Differences were significant at several vertebral levels in each of these dimensions. The narrowing of the intervertebral discs relative to the vertebral bodies in patients with carpal tunnel syndrome may indicate connective tissue changes, which might also occur in the common extensor origin at the elbow or in the contents of the carpal tunnel. 